\title{
Cryopreservation of horse semen with a liposome and trehalose added extender
}

\author{
Ariadna Z. Medina-León ${ }^{\mathrm{a}}$, Belisario Domínguez-Manceraa, Nicolás Cazalez-Penino ${ }^{\mathrm{b}}$, \\ Patricia Cervantes-Acosta ${ }^{a}$, Edelmira Jácome-Sosa $^{a}$, Dora Romero-Salas ${ }^{\text {a }}$, \\ Manuel Barrientos-Morales ${ }^{\mathrm{a}^{*}}$
}

\begin{abstract}
The aim of the study was to evaluate the effect of cryopreserved equine semen in the presence of trehalose-loaded liposomes on the integrity and function of sperm cells. Six ejaculations of five stallions collected with an artificial vagina were used. The ejaculates were diluted with INRA $96^{\circledR} 2: 1 \mathrm{v} / \mathrm{v}$ and transported at $22^{\circ} \mathrm{C}$ to the laboratory. Before cryopreservation, the semen was diluted with INRA Freeze ${ }^{\circledR}$ to obtain the following treatments: T1) INRA Freeze ${ }^{\circledR}$ (control), T2) INRA Freeze ${ }^{\circledR}+$ liposomes, T3) INRA Freeze $^{\circledR}+$ liposomes+trehalose. Data were analysed using the Kruskal Wallis test. The percentages of sperm with intact DNA were $54.5,57.9$, and $64.8 \%$ for $\mathrm{T} 1, \mathrm{~T} 2$ and $\mathrm{T} 3$, respectively $(P>0.05)$. When evaluating the acrosomal and capacitation state after filtering with Percoll ${ }^{\circledR}$, the percentages of spermatozoa without acrosome reaction and without capacitation were 67.8, 79.2 and 68.1\% in T1, T2, and T3, respectively $(P>0.05)$, while the capacitated sperm without acrosome reaction and without capacitation was similar in T1 $(47 \%)$ and T3 (32\%) $(P>0.05)$, and lower in T2 (16\%) before filtering with Percoll ${ }^{\circledR}$. The use of liposomes and liposome-trehalose did not affect on the functional status and nuclear chromatin of the equine sperm after freezing, but it did affect the percentage of capacitated sperm without acrosome reaction after selecting the thawed semen using the Percoll ${ }^{\circledR}$ gradient.

Key words: equine, semen, liposomes, trehalose.
\end{abstract}

\section{INTRODUCTION}

Variability in sperm viability after the freezing and thawing process is a factor that limits the frequent use of frozen semen in equine breeding programs. Differences are observed among individuals and ejaculates, and these changes can result in reduced fertility (Amann et al 1987). One of the causes of reduced sperm fertility is the freezing/ thawing process which damages cell components. The plasma membrane is the first affected site (Quinn et al 1980). Studies in this field have shown that the addition of liposomes to diluents before freezing can optimise membrane composition (Pillet et al 2012). It has also been shown that this damage can be reduced by adding lipoproteins to cryoprotectants (Wu et al 2013). It was found that the combination of external and internal cryoprotectants (Corcuera et al 2007) stabilises cell osmotic pressure and reduces stress. Trehalose is a polysaccharide with extracellular protective action which diminishes lesions caused by ice crystals. Its hypertonic effect causes cell dehydration, leading to a greater resistance of sperm against damage

Received: 24.05.2018.

Accepted: 03.01.2019.

aaracultad de Medicina Veterinaria y Zootecnia, Universidad Veracruzana, Veracruz, México.

bDepartamento de Reproducción Animal, Facultad de Veterinaria, Universidad de la República de Uruguay, Montevideo, Uruguay.

*Corresponding author: M Barrientos-Morales; Miguel Ángel de Quevedo s/n esq. Yáñez, Col. Unidad Veracruzana, C.P. 91710, Veracruz, México; mbarrientos@uv.mx during freezing and thawing, improving its viability and motility (Molinia et al 1994, Bucak et al 2007).

The effect of adding trehalose and liposomes during cryopreservation on equine sperm quality after thawing has not been reported yet. Therefore, it is important to determine the efficacy of the use of trehalose and liposomes on the integrity and functionality of cryopreserved equine sperm.

\section{MATERIAL AND METHODS}

\section{EJACULATES}

Six ejaculations from five stallions were used. All the ejaculations were collected during the reproductive season (spring-summer), twice on two consecutive days with an interval of one hour between collections. The stallions rested $48 \mathrm{~h}$ and ejaculations were collected again the day after resting. The last ejaculate was used for treatment application. To collect the semen, the penis was washed with warm water to remove smegma and avoid contamination of the sample. The semen was collected with an artificial vagina (Colorado model), using a mare in heat to stimulate the stallions. Only the fraction rich in spermatozoa was recovered and filtered. Ejaculations with $60 \%$ progressive motility were selected and evaluated by one technician, following recommendations of Maxwell et al (1998).

The ejaculates diluted with INRA $96^{\circledR}$ (IMV Technologies ${ }^{\circledR}$, France) at a ratio of $2: 1 \mathrm{v} / \mathrm{v}$ at $22^{\circ} \mathrm{C}$ were transported at a temperature of $37^{\circ} \mathrm{C}$ to the Reproduction Biology Laboratory of the Diagnostic Unit of the "Torreón del Molino" Zootechnical Farm, FMVZ-UV, where they were processed. 


\section{CONCENTRATION AND SEMINAL DILUTION}

The semen was assessed to determine sperm concentration, as described by Brito et al (2016). Once sperm concentration was obtained, the semen was centrifuged to form a pellet, which was later re-suspended with the commercial freezer diluent INRA Freeze ${ }^{\circledR}$ (IMV Technologies ${ }^{\circledR}$, France), following the manufacturer's instructions, and the sample was homogenised. Once the semen was diluted, three aliquots were separated from each ejaculate to be used in the treatments.

\section{TREATMENTS}

After diluting the semen, a $5 \mathrm{ml}$ aliquot was assigned to one of the following treatments:

1) $\mathrm{T} 1$ (control): Semen diluted in INRA Freeze ${ }^{\circledR}$ without egg yolk.

2) T2: INRA Freeze ${ }^{\circledR}$ and liposomes $50 \mu \mathrm{l}$.

3) T3: INRA Freeze ${ }^{\circledR}$ and liposomes $50 \mu \mathrm{l}$ and $200 \mathrm{mM}$ trehalose.

\section{PREPARATION OF LIPOSOMES}

To prepare the liposomes, we used a commercial kit (SIGMA-ALDRICH ${ }^{\circledR}$ ) consisting of a mixture of lipids such as cholesterol ( $9 \mu \mathrm{mol}), \mathrm{L}-\alpha$-phosphatidylcholine (egg yolk, $63 \mu \mathrm{mol})$, and stearylamine $(18 \mu \mathrm{mol})$. The preparation was made following the instructions of the manufacturer: $1000 \mu \mathrm{l}$ of deionized water was added, the mixture was then homogenised by vortex for 30 seconds and stored under refrigeration until use.

\section{PREPARATION OF DILUENT WITH TREHALOSE}

To prepare the trehalose solution, $1 \mathrm{ml}$ of deionized water was mixed with $200 \mathrm{mM}$ of trehalose (Fluka Analytical, UK) and vortexed to homogenise the solution.

\section{FREEZING}

To determine the sperm concentration of each ejaculate, sperm count was performed in a hematocytometer, using the technique described by Brito (2016). Once subjected to the different treatments, the diluted semen was deposited into $0.5 \mathrm{ml}$ straws at a concentration of 200 million sperm per $\mathrm{ml}$. They were refrigerated at $4{ }^{\circ} \mathrm{C}$ for $75 \mathrm{~min}$ and exposed to liquid nitrogen for 20 minutes (Ramires et al 2014). The freezing curve was performed in two steps: the semen straws are first cooled at a rate of $3{ }^{\circ} \mathrm{C}$ to $5{ }^{\circ} \mathrm{C}$ per minute until they reach $5{ }^{\circ} \mathrm{C}$. They are then frozen at a rate of $20^{\circ}$ to $50^{\circ} \mathrm{C}$ per minute until reaching $-196{ }^{\circ} \mathrm{C}$. Isothermal boxes were used for freezing: $45 \mathrm{~L}$ polystyrene foam boxes in which the nitrogen and straws were separated by 3 to $6 \mathrm{~cm}$ (Alvarenga et al 2015). After
30 minutes, the straws were immersed in liquid nitrogen and deposited inside a tank with liquid nitrogen.

\section{THAWING}

To assess the effect of the treatments on the motility, acrosome state, and integrity of the nuclear chromatin, straws of each treatment were thawed. Thawing was done by placing the straws in a water bath at $37^{\circ} \mathrm{C}$ for 30 seconds (Ramires et al 2014).

\section{SPERM SEPARATION}

To obtain a more appropriate sample of viable sperm, the sperm was separated through Percoll ${ }^{\circledR}$ gradients. Sperm separation was done in the following steps: 3 conical tubes with a capacity of $15 \mathrm{ml}$ were used. In each tube, $0.5 \mathrm{ml}$ of Percoll ${ }^{\circledR}$ was placed with a concentration gradient of $60 \%$. Then, to each tube, $0.5 \mathrm{ml}$ of Percoll ${ }^{\circledR}$ was added at a concentration of $40 \%$, and finally, $0.5 \mathrm{ml}$ of semen samples from each treatment was added in each tube. The samples were centrifuged at $3000 \mathrm{rpm}$ for $3 \mathrm{~min}$, the pellet was separated, and each pellet was resuspended in PBS and incubated for $15 \mathrm{~min}$ at $37^{\circ} \mathrm{C}$. Then, mass motility was observed and viability was estimated.

\section{EVALUATION OF THE INTEGRITY OF THE ACROSOME}

To determine the acrosomal state, the chlortetracycline fluorescence technique was used (Das Gupta et al 1994).

The following solutions were used:

- Buffered solution: $130 \mu \mathrm{mol} \mathrm{NaCl}, 5 \mu \mathrm{mol}$ cysteine, $20 \mu \mathrm{mol}$ Tris- $\mathrm{HCl}$ (pH 7.8).

- Chlortetracycline solution (CTC): $750 \mu \mathrm{mol}$ of CTC in buffered solution.

- $12 \%$ Paraformaldehyde in 0.5 moles Tris- $\mathrm{HCl}$ buffer (pH 7.4).

- DABCO: 0.22 mol DABCO ${ }^{\circledR}$ in glycerol solution and PBS (9:1).

The contents of a previously thawed semen straw were placed in a $2 \mathrm{ml}$ vial and centrifuged for $3 \mathrm{~min}$ at 323 $g$. The supernatant was removed and reconstituted with $80 \mu \mathrm{l}$ of PBS and $100 \mu \mathrm{l}$ of the CTC solution and shaken; $10 \mu \mathrm{l}$ of the paraformaldehyde solution was added to the mixture and stirred. The slides were prepared by placing $10 \mu \mathrm{l}$ of the sample on a clean slide and adding a drop of $\mathrm{DABCO}^{\circledR}$ solution to prolong the fluorescence. A slide cover was placed on the sample and observed under a fluorescence microscope.

The following fluorescence patterns were observed:

- Uniform fluorescence throughout the head and the middle part: not trained, no acrosomal reaction. 
- Non-fluorescent band in the post-acrosomal region: trained, no acrosomal reaction.

- No fluorescence in the head, only in the intermediate piece: trained, with acrosomal reaction.

\section{EVALUATION OF THE INTEGRITY OF NUCLEAR CHROMATIN}

DNA integrity was evaluated using the fluorescence technique with acridine orange (NA), as described by (Tejeda et al 1984). The contents of a previously thawed semen straw were deposited into a $2 \mathrm{ml}$ tube and centrifuged at $300 \mathrm{~g}$ for $3 \mathrm{~min}$. The supernatant was removed, $100 \mu \mathrm{l}$ of PBS were added and a smear was made with 20 $\mu l$ of the sample. When the smear was dry, it was placed in Carnoy's solution for $24 \mathrm{~h}$, after which it was removed from the solution and dried, and $50 \mu \mathrm{l}$ of citric acid was added. After $5 \mathrm{~min}$, it was rinsed with deionized water, dried, stained with the orange acridine solution for $5 \mathrm{~min}$, rinsed with deionized water, drained and covered with a slide cover. It was immediately observed in the fluorescence microscope (Leica DM 020-518500/LS) with blue excitation filter from 405 to $455 \mathrm{~nm}$, with a 40x objective. Several fields were observed to count 200 cells. The following fluorescence patterns were observed: Green sperm $=$ intact DNA; Orange or red sperm $=$ denatured DNA.

\section{STATISTICAL ANALYSIS}

The results were analysed statistically by one-way analysis of variance with the statistical package of the program Statistics v. 10 and Sigmaplot v. 13.

\section{RESULTS AND DISCUSSION}

\section{POST-THAWING MOTILITY}

The use of liposomes and trehalose as cryoprotectants has been studied with different animal species. They protect sperm by limiting the damage to the cell membrane during cooling, freezing and thawing. Figure 1 shows the average individual motility obtained after the thawing process for each treatment. An increase in motility is observed in cryopreserved samples with liposomes $(33.3 \%)$ relative to the control samples (25.8\%), 7.5\% higher. In contrast, samples with liposomes loaded with trehalose $(15.8 \%)$ were $10 \%$ lower $(P>0.05)$ in motility than the control samples. It has already been shown that in horses, the addition of liposomes, relative to other components (egg yolk, skimmed milk, and glycerol), are more effective in preserving post-thaw motility (Denniston et al 1997). In this project, greater post-thaw progressive motility was observed in the samples frozen with the freezing diluent INRA Freeze ${ }^{\circledR}$ and liposomes (33.33\%) than in the control treatment and in that of liposomes with trehalose $(P<0.05)$. These results are similar to the $31.4 \%$ spermatozoa with progressive motility reported by Belala et al (2016). On the other hand, the result of the treatment using only the INRA Freeze ${ }^{\circledR}$ diluent $(25.8 \%)$ is similar to the $26.5 \%$ obtained by Najjar et al (2016). The difference observed between these two treatments (T1 and T2) can be attributed to the stimulating effect of liposomes (Pillet et al 2012) on the freezing diluent, compared with the use of egg yolk. Although trehalose helps to reduce damage to the plasma membrane, it could increase the density of the medium, causing a decrease in motility.

FUNCTIONAL STATUS OF SPERM AFTER THAWING, BEFORE, AND AFTER FILTRATION WITH PERCOLL ${ }^{\circledR}$

The assessment of the integrity of the acrosome of the six thawed ejaculates and their comparison before and after filtering showed a statistical difference in the percentage of untrained sperm without acrosome reaction in the liposome and liposome treatments with trehalose $(P<0.05)$. There were no differences between treatments after post-thaw filtration $(P>0.05)$ (figure 2$)$. After thawing, it is important to use sperm selection procedures to recover a highly functional sperm population and achieve optimal conception rates (Stoll et al 2013, Cabera et al 2014). This selection is made through centrifugation in density gradients, in this case Percoll ${ }^{\circledR}$, which has been catalogued as a method to select significantly higher percentages of spermatozoa with intact acrosome (Brandies et al 1993, Somfai et al 2002). The results of this study showed that the proportion of untrained sperm with no acrosomal reaction was not statistically different $(P>0.05)$ after filtration with Percoll ${ }^{\circledR}$. However, it was observed that the process is effective for the selection of a cell population with greater viability since sperm quality is low $(<45 \%)$ before filtration (figure 2$)$. It has been shown that

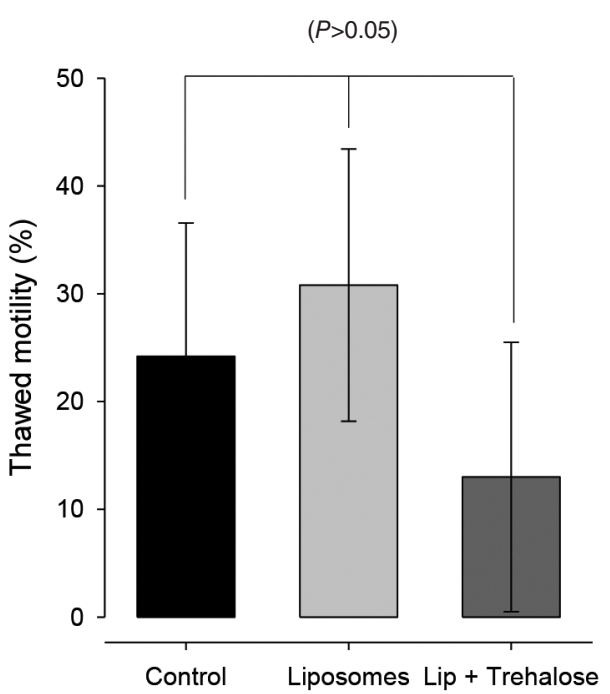

Figure 1. Post-thaw evaluation of motility of equine spermatozoa subjected to different cryopreservation treatments. 


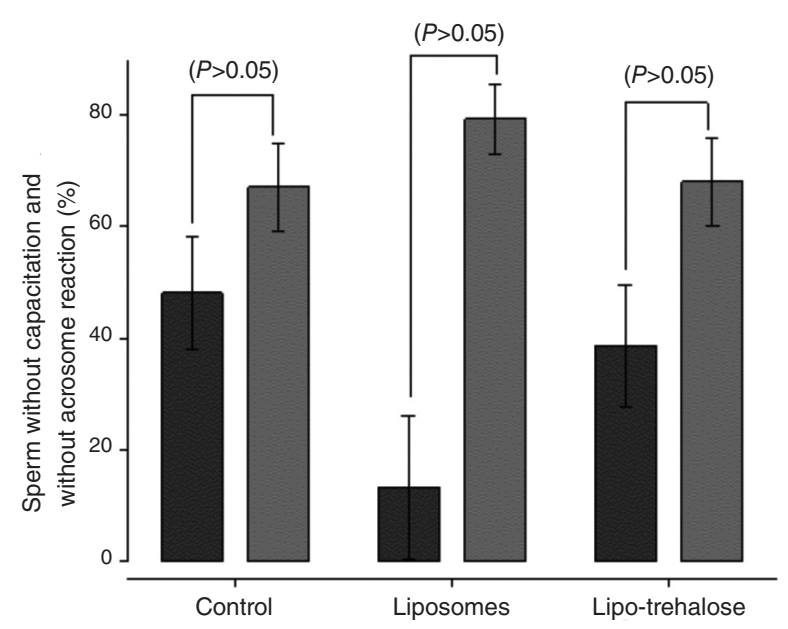

Figure 2. Post-thaw evaluation of the functional status of equine spermatozoa subjected to different cryopreservation treatments and filtering with Percoll ${ }^{\circledR}$.

the addition of exogenous phospholipids and liposomes protect the sperm cell from damage during the freezing/ thawing process since they maintain stability in the plasma membrane by fusing it (Köse et al 1998). Likewise, it has been demonstrated that the addition of polysaccharides such as trehalose contributes to the protection of the plasma membrane in the freezing/thawing process by dehydrating the cell and decreasing the transition temperature of the phospholipids (De Leeuw et al 1993).

\section{INTEGRITY OF NUCLEAR CHROMATIN}

The integrity of the nuclear chromatin in the thawed semen included in the three treatments was evaluated. The control treatment $(54.5 \%)$ was statistically different $(P<0.05)$ from that of the liposomes loaded with trehalose (64.8\%). DNA integrity is a very important factor when evaluating sperm fertility as it is reflected in the ability to maintain embryonic development (Hamamah et al 1990). In this study, it was evaluated with acridine orange. The results showed no statistical differences between the proposed treatments $(P>0.05)$ (table 1). However, our results are

Table 1. Post-thaw evaluation of the integrity of the nuclear chromatin of equine spermatozoa subjected to different cryopreservation treatments.

\begin{tabular}{lcc}
\hline Treatments & $\begin{array}{c}\text { Intact DNA } \\
\%\end{array}$ & $\begin{array}{c}\text { Denatured DNA } \\
\%\end{array}$ \\
\hline Control & $54.5 \pm 0.047$ & $45.5 \pm 0.052$ \\
Liposomes & $57.9 \pm 0.045$ & $42.1 \pm 0.053$ \\
Liposomes/trehalose & $64.8 \pm 0.042$ & $35.2 \pm 0.056$ \\
\hline
\end{tabular}

Without statistical difference between columns $(P>0.05)$. markedly different from those reported by other authors (Moreno et al, Belala et al 2016). This may be due to the cryopreservation technique used (Röpke et al 2011) or to the tolerance variability to the freezing/thawing process among stallions (Amann et al 1987).

In conclusion, this study indicates that the enrichment of the freezing diluent INRA Freeze ${ }^{\circledR}$ with liposomes and liposomes plus trehalose in equine sperm does not provide better results in terms of progressive motility or preservation of DNA integrity compared with the use of INRA Freeze ${ }^{\circledR}$ diluent alone. However, filtering using density gradients with Percoll ${ }^{\circledR}$ can raise sperm quality after thawing by recovering the cells with greater viability.

\section{REFERENCES}

Alvarenga MA, Ozanam F, Ramires C. 2015. Cryopreservation of Stallion Semen. In: KA Sprayberry, NE Robinson (eds). Robinson's Current Therapy in Equine Medicine. $7^{\text {th }}$ ed. Saunders Elsevier, St Louis, Mo, USA, Pp 663-664.

Amann R, Pickett B. 1987. Principles of cryopreservation and a review of cryopreservation of stallion spermatozoa. J Equine Vet Science 7, 145-173.

Ansari MS, Rakha BA, Akhter S, Ashiq M. 2016. OptiXcell improves the postthaw quality and fertility of buffalo bull sperm. Theriogenology $85,528-532$.

Belala R, Delay J, Amirat L, Ropers MH, Guillou JL, et al. 2016. The benefits of liposomes for chilling canine sperm for 4 days at $4{ }^{\circ} \mathrm{C}$. Ani Reprod Sci 168, 100-109.

Brito L, Althouse G, Aurich C, Chenoweth P, Eilts B, et al. 2016. Andrology laboratory review: Evaluation of sperm concentration. Theriogenology 85, 1507-1527.

Bucak M, Atessahin A, Varıs L, Yuce A, Tekin N, et al. 2007. The influence of trehalose, taurine, cysteamine and hyaluronan on ram semen: microscopic and oxidative stress parameters after the freeze-thawing process. Theriogenology 67, 1060-1067.

Corcuera B, Marigorta P, Sagüés A, Saiz-Cidoncha F, Pérez-Gutiérrez JF. 2007. Effect of lactose and glycerol on the motility, normal apical ridge, chromatin condensation and chromatin stability of frozen boar spermatozoa. Theriogenology 67, 1150-1157.

Das Gupta S, Mills S, Fraser L. 1994. A possible role for $\mathrm{Ca}^{2+}$-ATPase in human sperm capacitation. J Reprod Fertil 102, 107-116.

De Leeuw F, De Leeuw A, Dendaas J, Colenbrander B, Verkleij A. 1993. Effects of various cryoprotective agents and membrane- stabilizing compounds on bull sperm membrane integrity after cooling and freezing. Cryobiology 30, 32-44.

Denniston DJ, Graham JK, Squires EL, Brinsko SP. 1997. The effect of liposomes composed of phosphatidylserine and cholesterol on fertility rates using frozen thawed equine spermatozoa. J Equine Vet Sci 17, 675-676.

Hamamah S, Royere D, Nicolle JC, Paquignon M, Lansac J. 1990. Effects of freezing-thawing on the spermatozoon nucleus: a comparative chromatin cytophotometric study in the porcine and human species. Reprod Nutr Dev 30, 59-64.

Kheirolomoom A, Satpathy GR, Torok Z, Banerjee M, Bali R, et al. 2005. Phospholipid vesicles increase the survival of freeze-dried human red blood cells. Cryobiology 51, 290-305.

Köse GT, Arica MY, Hasirci V. 1998. Low-molecular-weight heparin-conjugated liposomes with improved stability and hemocompatibility. Drug Delivery 5, 257-264.

Kumar P, Sainia M, Kumar D, Balharaa A, Yadava S, et al. 2015. Liposome-based semen extender is suitable alternative to egg yolkbased extender for cryopreservation of buffalo (Bubalus bubalis) semen. Anim Reprod Sci 159, 38-45. 
Maxwell W, Long C, Johnson L, Dobrinsky L, Welch G. 1998. The relationship between membrane status and fertility of boar spermatozoa after flow cytometric sorting in the presence or absence of seminal plasma. Reprod Fertil Dev 10, 433-440.

Molinia F, Evans G, Casares P, Maxwell W. 1994. Effect of monosaccharides and disaccharides in tris-based diluents on motility, acrosome integrity and fertility of pellet frozen ram spermatozoa. Anim Reprod Sci 36, 113-122.

Moreno JMM, Harris ME, Breda J, Møller L, Sanchez JLA, et al. 2013. Enhanced labelling on alcoholic drinks: reviewing the evidence to guide alcohol policy. Eur J Public Health 23, 1082-1087.

Mutalik S, Salian SR, Avadhani K, Menon J, Joshi H, et al. 2014. Liposome encapsulated soy lecithin and cholesterol can efficiently replace chicken egg yolk in human semen cryopreservation medium. Syst Biol Reprod Med 60, 183-188.

Najjar A, Saïd SB, Kalamoun S, Benaoun B, Ezzaouia M, et al. 2016. Comparison of two freezing extenders and their influence on sperm quality of Tunisian Arab stallions. J Vet Sci Anim Husb 4, 302.

Pillet E, Labbe C, Batellier F, Duchamp G, Beaumal V, et al. 2012. Liposomes as an alternative to egg yolk in stallion freezing extender. Theriogenology 77, 268-279.

Quinn P, Chow P, White I. 1980. Evidence that phospholipid protects ram spermatozoa from cold shock at a plasma membrane site. J Reprod Fert 60, 403-407.
Ramires NC, Monteiro GA, Sancler-Silva YFR, Papa P, Guasti P, et al. 2014. Comparison of different freezing extenders for semen cryopreservation from stallions with poor and good semen freezability. J Equine Vet Sci 34, 58-60.

Röpke T, Oldenhof H, Leiding C, Sieme H, Bollwein H, et al. 2011. Liposomes for cryopreservation of bovine sperm. Theriogenology 76, 1465-1472.

Tejada R, Mitchell C, Norman A, Marik J, Friedman S. 1984. A test for the practical evaluation of male fertility by acridine orange (AO) fluorescence. Fertil steril 42, 87-91.

Vera-Munoz O, Amirat-Briand L, Bencharif D, Anton M, Desherces S, et al. 2011. Effect of low-density lipoproteins, spermatozoa concentration and glycerol on functional and motility parameters of bull spermatozoa during storage at $4{ }^{\circ} \mathrm{C}$. Asian J Androl 13, 281-286.

Watson PF. 1981. The roles of lipid and protein in the protection of ram spermatozoa at 5 degrees $C$ by egg-yolk lipoprotein. $J$ Reprod Fertil 62, 483-492.

Wilhelm K, Graham J, Squires E. 1996. Effects of phosphatidylserine and cholesterol liposomes on the viability, motility, and acrosomal integrity of stallion spermatozoa prior to and after cryopreservation. Cryobiology 33, 320-329.

Wu T, Cheng F, Chen I, Yang C, Tsai C, et al. 2013. The combinatorial effect of different Equex STM paste concentrations, cryoprotectants and the straw-freezing methods on the post-thaw boar semen quality. Reprod Domest Anim 48, 53-58. 
